\title{
Sobre la posibilidad de un mito sororo
}

\section{The possibility of a Sisterhood Myth}

\begin{abstract}
RESUMEN
En las siguientes líneas analizaremos la escena mítica que ocurre entre dos figuraciones femeninas, a saber: Baubo y Deméter. Nuestro interés en señalar dicha escena responde a rescatar una narración de alianza femenina frente a los relatos de rivalidad entre diosas, entre estas y mujeres y, también, frente a los relatos de fraternidad entre figuraciones masculinas. Rescatar este mito nos permite reconstruir la imagen de un espacio seguro para mujeres, un lugar en el que compartir vida y muerte, dolor y alegría. Para ello, recurriremos a las fuentes originales que nos transmiten esta escena, así como a reflexiones contemporáneas sobre este mito. Pasaremos a analizar los elementos que configuran la narración a fin de ofrecer una interpretación general que nos lleve a extraer una serie de consideraciones acerca de la posibilidad de una alianza genuina entre mujeres.
\end{abstract}

Palabras clave: Baubo, Deméter, sexo femenino, obscenidad, alianza.

\section{Abstract}

We will analyse a mythical scene between two female figurations: Baubo and Demeter. Our interest is to rescue a narrative of female alliance from the stories of rivalry between goddesses and between these and women, and from the stories of brotherhood between male figurations. This myth allows us to rebuild the image of a safe space for women, a place in which to share life and death, pain and joy. To achieve our goal, we will turn to the original sources as well as contemporary reflections on this myth. We will go on to analyse the elements that make up the narrative, developing the implications that they could have for women in order to offer a general interpretation that leads us to extract considerations about the possibility of a genuine alliance between women.

Keywords: Baubo, Demeter, female sex, obscenity, alliance.

\section{SUMARIO}

1.- Introducción. 2.- Escena mítica. 3.- Elementos del mito. 4.- Conclusiones o derivas de nuestro planteamiento. -Bibliografía.

\section{1.- Introducción}

Para nuestro estudio partiremos del texto de la filósofa francesa Sarah Kofman, titulado «Baubô, perversion théologique et fétichisme» de 1975. En él, se expone una escena del mito del rapto de Perséfone y la búsqueda que emprende su madre, Deméter, diosa griega de la fertilidad, de la agricultura y de los cereales, en específico, de la cebada. Nuestra autora fija la atención en una escena lúgubre, en la que Deméter, exhausta tras vagar durante nueve días y nueve noches, en los que 
ni bebe ni come, se encuentra con una mujer llamada Baubo. Esta mujer logra que Deméter rompa su ayuno y supere su melancolía dando paso al trabajo del duelo (cf. Maseda, 2020: 345).

Sarah Kofman trae la figura de Baubo en su desarrollo a propósito del fetichismo existente en la cultura, entendido como un no querer ver la diferencia sexual, pero reconocerla y, por tanto, disfrazarla. Para poner este fetichismo en cuestión, nos trae esta escena donde se da una genuina alianza entre mujeres. Una alianza forjada en el seno de la tristeza, de la pérdida y del dolor. Del rechazo de la vida. Pero también de hospitalidad, acogimiento, en un ofrecer gratuito, sin esperar nada a cambio. Un relato donde la lógica, que se ha denominado fálica desde el psicoanálisis y la deconstrucción, queda neutralizada por otra lógica, que se desarrolla a través del mostrar y de la risa. Sin palabras, sin racionalidad, tan solo remitiendo al cuerpo, a la inmanencia, en un intercambio de miradas entre iguales, en un espacio de seguridad, en el que se pone en juego el dolor, su asunción y la posibilidad de salir de él.

Nos parece importante la escena que estudiaremos dado que encontramos todo un repertorio de mitos de alianzas y hermandad masculinas — valgan como ejemplo los relatos sobre los argonautas o sobre la tripulación de Odiseo. Y, sin duda, también hallamos historias de rivalidad entre figuraciones femeninas, como las de Hera maldiciendo a Eco porque Zeus se fija en ella; Atenea haciendo de Medusa un ser monstruoso porque Apolo la había violado en el templo dedicado a la diosa; Afrodita y la maldición sobre Psique; Artemisa y su castigo a Calisto o el conflicto creado por la manzana de Eris entre Atenea, Afrodita y Hera, pues todas querían ser la diosa más bella.

En la escena que presentamos pretendemos poner de relieve la sororidad. Enfocada a partir del pensamiento de Sarah Kofman podría ser entendida como la unión de las mujeres en su aparecer como humanas, demasiado humanas, es decir, en el reconocimiento de lo que hay, en la inocente crueldad y en la potencia de la vida.

\section{2.- Escena mítica}

Baubo, en principio, es un personaje secundario, que en nuestro texto, a partir de aquellos que conforman nuestra base de interpretación, se convertirá en personaje principal, junto con Deméter. Las fuentes que dan lugar a las interpretaciones y distintos estudios sobre esta escena son dos: de una parte encontramos los relatos órficos y de la otra el Himno homérico a Deméter ${ }^{2}$. Señalamos que en esta última versión aparece Yambe en el papel de Baubo, cuestión a la que dedicaremos unas líneas más adelante. Comenzaremos por la exposición que hace nuestra autora del mito:

Baubo es un personaje que interviene en los misterios de Eleusis consagrados a Deméter: ella hace reír a Deméter, diosa la fecundidad, que tras la desaparición de

2 Para un estudio detallado sobre esta escena remitimos a la tesis doctoral El mito de Proserpina: Fuentes grecolatinas y pervivencia en la literatura española de M. ${ }^{a}$ Dolores Castro Jiménez, pp. 58 y ss. 
Perséfone, afectada por el dolor, comenzó a comportarse como una mujer estéril: durante nueve días y nueve noches, ni bebió, ni comió, ni se bañó ni se acicaló.

Baubo hace reír a Deméter al levantar sus faldas y mostrar su vientre, sobre el cual hay dibujada una figura (se ha creído reconocer aquí la de Yaco, hijo de Deméter, divinidad incierta, identificada a veces con Dionisos). Este episodio es conocido por seis versos órficos muy censurados calificados de oscuros por los padres de la Iglesia. (1979: 294. Nuestra traducción.)

Una versión cercana a esta será la que nos ofrezca Clemente de Alejandría ${ }^{3}$ en su Protréptico:

Cuando Deo [Deméter] estaba errante a la búsqueda de su hija Core [Perséfone], se sintió desfallecer en los alrededores de Eleusis (lugar de Ática) y, entristecida, se sentó en un pozo [...].

Habitaban Eleusis entonces hombres autóctonos: sus nombres eran Baubó, Disaules, Triptólemo, Eumolpo y Eubuleo [...].

Ciertamente (pues no voy a dejar de contarlo), Baubó, que había recibido a Deo en hospitalidad, ofreció a la diosa «ciceón», pero ella rechazó cogerlo y no quiso beberlo (puesto que se encontraba en duelo). Baubó se entristeció mucho pensando que la despreciaba y entonces, levantando su túnica, muestra su desnudez a la diosa. Deo se divierte con el espectáculo y a duras penas acepta la bebida, alegre con la visión.

¡Éstos son los misterios ocultos de los atenienses! También los cuenta Orfeo. Te citaré sus mismos versos, para que tengas como testigo al «mistagogo» de esta desvergüenza:

Después de hablar así, se subió el peplo y mostró todo su cuerpo, hasta las formas que menos convienen. Se encontraba presente el niño Yaco y, riéndose, le golpeaba con la mano por debajo del pecho. Y, cuando la diosa se sonrió en su corazón, aceptó la multicolor copa, donde se hallaba el ciceón. (II, 20-21)

En la versión de Robert Graves (1996: 92) leemos que Deméter, disfrazada de anciana, en su deambular llega a Eleusis, donde es hospedada por el rey Céleo. Una de sus esclavas, llamada Yambe ${ }^{4}$, comienza a recitar versos lascivos ante la diosa a fin de alejar su aflicción. A la vez, una vieja niñera llamada Baubo imita un parto y Yaco, el hijo de Deméter, asoma por debajo de su falda. De un salto se lanza a los brazos de su madre y la besa. Con esta escena acepta la diosa beber la copa de ciceón. Asimismo, nos indica el autor que tanto «Yambe» como «Baubo» refieren a un tipo de canciones obscenas, hechas en métrica yámbica, entonadas durante los misterios eleusinos.

Karl Kerényi (1994) escribe sobre el marido de Baubo: «Su nombre indica que posee una granja, vivienda y rebajos pobres y humildes» (33). Y sobre la propia

3 Hemos de tener en cuenta que este fragmento forma parte de una recopilación que responde a una valoración crítica sobre los cultos anteriores al cristiano. «El material órfico ha sobrevivido principalmente en relatos (hostiles) de los Padres de la Iglesia del culto de Deméter; aunque claramente desean enfatizar la naturaleza ridícula y obscena de los ritos paganos, los eventos descritos se ajustan a los mitos de fertilidad en otros lugares» afirma Laurie O'Higgins (2003: 52).

4 Hija de Pan y Eco, relacionada con la diosa del humor y de la poesía, de las bromas groseras, eróticas (cf. Smith, 1876: 548). 
mujer que es «una criatura robusta e impúdica, también con nombre significativo, pues aparece en Empédocles con el significado de «barriga» (33). El hijo de esta pareja es quien pudo indicar a Deméter el camino para encontrar a Perséfone, dado que los cerdos que criaba fueron tragados por la tierra cuando esta se abrió por Hades en el momento del rapto de la joven. Este mismo autor en Eleusis. Imagen arquetípica de la madre y de la hija escribe:

Cuando la diosa se sentó allí sin reír, en los alojamientos de Metanira o en la roca, Yambe, la amable doncella, desempeñó su función. Su nombre era Yambe, como el metro de los poemas yámbicos, esto es, satíricos, pero en forma femenina y no masculina. Su función era hacer que Deméter riera con bromas y burlas, para convertir su pena en ternura (200-204). Lo consiguió por medio de gestos obscenos, que el estilo del poeta homérico le prohíbe describir. Pero existe otra versión, algo de la cual ha llegado hasta nosotros. La atmósfera de los festivales de Deméter permitía juegos y cuentos groseros. Según esta versión, no había entonces ningún rey en Eleusis, sino sólo un pobre campesino con su familia. [Su] nombre era Disaules «aquel en cuya choza no era bueno vivir». Su esposa Baubo también tenía un nombre elocuente: significaba «vientre». Ella no dudó en realizar una danza obscena ante la diosa y en echarse de espaldas. De esta manera, hizo que Deméter riera. En el Himno homérico, Yambe hacía lo mismo con sus chanzas. (2004: 64)

La otra fuente en la que se basan los estudios sobre esta escena la encontramos en el Himno a Deméter (1978):

Allí sentándose dejó caer ante su rostro con las manos el velo; largo tiempo, sin voz, afligida, estuvo sentada en el asiento y a nadie saludaba ni de palabra ni con un gesto, sino que, sin reír, sin catar comida ni bebida, sentada estaba, consumida por la añoranza de su hija de marcada cintura; hasta que, con sus chanzas, Yambe, sabedora de discretos pensamientos, con sus muchas burlas movió a la soberana sin mancilla a sonreír, a reír y a tener buen ánimo; ésta a ella luego, en adelante, le cayó en gracia a su espíritu.

A la diosa una copa Metanira le daba de vino dulce como miel tras llenarla: pero ella la rechazó, pues decía que no le era permitido beber vino tinto, y exhortaba a que malta y agua le dieran a beber, tras mezclarlas con menta suave. Ésta, tras hacer el ciceón, a la diosa se lo dio como ordenaba. (vv. 196-210)

\section{3.- Elementos del mito}

\section{Baubo}

Kofman, en su texto sobre Baubo, trae una cita de Nietzsche en la que se refiere a Baubo como «la vida» (cf. Nietzsche, 2014: 721). Al respecto, nuestra filósofa escribe: «Llamar a la vida «Baubo", es identificarla no solo con la mujer, sino específicamente, con sus órganos de reproducción: Baubo es el equivalente de Koilia (múltiples nombres en griego para designar el sexo femenino)» (Kofman, 1979: 295296. Nuestra traducción). 
Pierre Chantraine en Dictionnaire étymologique de la langue grecque (1968: 170), en

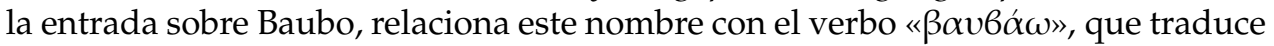
como 'dormir' y como 'dormir a alguien'. Sus variantes apuntan a 'acunar' y 'cantar una nana' y por derivación también 'mimar' o 'arropar'. Además, el nombre de Baubo designa el sexo femenino, evoca a la niñera o nodriza de Deméter y a la mujer llamada Baubo de nuestro mito. El filólogo, a la luz de estas significaciones, sostiene que habría que buscar un nexo entre ellas, que, por cierto, encontramos en el mito: abrazar, calmar, mecer, acciones que podemos vincular al efecto que tiene el gesto de Baubo ante Deméter, al revitalizarla calmando su aflicción, al impulsar su voluntad de vida, más allá de la muerte y de la pérdida. No se trata, sin embargo, de un gesto narcotizante, sino más bien de un gesto que mima y calma, en la complicidad, desde la alianza: un gesto de afirmación radical de la vida, y de la crueldad que esta conlleva.

William K. C. Guthrie caracteriza a Baubo como una especie de duende dentro del imaginario popular de la primitiva Grecia, que en tiempos posteriores queda asociada a Hécate y, con ello, a lo oculto, a la noche y a la brujería. Sin embargo, su nombre significa, en un principio, simplemente «lo que mostró a Deméter», un emblema vulvar (1970: 136). En esta dirección, es interesante resaltar que el término griego $\beta \alpha v \beta \omega$ v significa 'dildo'. Jean-Pierre Vernant en La muerte en los ojos, escribe:

El phallós también llamado baubon para destacar su parentesco con Baubo, asume una función simétrica en el polo opuesto de lo monstruoso. Por lo general se asocia a lo cómico, acentúa el grotesco de esos monstruos divertidos que son los sátiros, pero en los ritos de iniciación provoca un terror sagrado, de espantada fascinación que reproduce los gestos de ciertos personajes femeninos al retroceder ante el phallós descubierto. (45-46)

Acerca de esta familiaridad entre los términos, Kofman enlaza la figura de Baubo con la de Dionisos a través de baubon. La conexión la encontramos en otra escena mítica: Dionisio en su viaje hacia el Hades, se encuentra con Prosimno, un joven por el que se siente atraído y con el que mantiene relaciones sexuales. Prosimno fallece y Dionisos talla un falo de madera de higuera en su recuerdo, llamado Baubon. Así, Baubon — falo- y Baubo — vulva—, resultan la concreción de los dos sexos, empleados simbólicamente en los ritos eleusinos. Nuestra autora también nos explicita que «en los misterios eleusinos, el órgano sexual femenino era exaltado como símbolo de la fecundidad, como garantía de la regeneración y del eterno retorno de las cosas» (Kofman, 1979: 296). Baubo como la doble, como la otra cara de Dionisos, compartiría con él la afirmación radical de la vida, más allá de la vida, de la muerte, de la separación, de la unión, en la inmanencia del constante devenir.

Asimismo, ciertos estudios hablan de la influencia egipcia sobre esta figura y emparentan a Baubo con la diosa rana del nacimiento Heqt, diosa de la fertilidad y de los partos. Recordemos que Baubo, según algunas interpretaciones es la comadrona de Deméter o incluso su niñera, lo que apunta a ciertas capacidades como cuidadora y curadora. En cualquier caso, símbolo de vida. Esta equivalencia viene impulsada por la posición corporal que adoptaría Baubo, ya que recuerda a las ra- 
nas. Sin embargo, tal como apunta en «Female Fertility Figures» Margaret Murray, la ecuación Baubo-Hécate y Baubo-Heqt no se sostiene filológicamente (1934: 95). Marija Gimbutas, en The Living Goddesses conecta la representación de Baubo-rana con las hipótesis de Margaret Murray y sostiene que Baubo y las figurillas del tipo «mujer-rana» se encuentran ya en Anatolia en el milenio VII. En consecuencia, podríamos encontrar en el neolítico figuraciones que apuntan aquello que señala la Baubo de nuestra escena mítica (1999: 28-29).

Otros estudios ponen de manifiesto un desplazamiento entre Baubo-Hécate, propiciado por el animal asociado a ellas, la rana, puesto que la forma en la que se ha representado a Baubo en algunas figurillas recuerda a las ranas, que es, precisamente, un animal asociado a Hécate, por lo que puede implicar una sustitución posterior o, incluso, que «Baubo» sea otro nombre de Hécate:

Es la propia Hécate la que se llama Baubo, una sapo hembra. Es evidente, por esto, que los órficos, por la analogía de sus nombres, habían comparado a Hécate a la diosa egipcia Heke-t, cuyo animal sagrado es la rana, símbolo de producción y multiplicación indefinida, y que a veces se representa en monumentos con la cabeza de una rana. "Baubo, en cuclillas, con las rodillas levantadas», comenta M. de Longpérier, ofrece una analogía bastante sorprendente con el sapo hembra o la rana. La parte que tuvieron los elementos egipcios en estas combinaciones híbridas explica cómo las figurillas de Baubo, en terracota y en vidrio, se encuentran principalmente en Egipto, donde fueron talladas durante los periodos griego y romano. (Lenormant, 1877: 683. Nuestra traducción)

Sobre la identificación con Hécate encontramos en la entrada «Baubo» de John G. R. Forlong, donde sostiene que Baubo «aparece como idéntica a Hécate (la luna) en los Papiros mágicos [...] Hécate era llamada Phroune o «rana» (2008: 269. Nuestra traducción). De estas reflexiones señalamos, de nuevo, las referencias al binomio Baubo-rana como creación, reproducción, multiplicación indefinida, lo que desde Kofman podríamos denominar afirmación radical de la vida, que siempre implica muerte, destrucción, desaparecer, crueldad... todo ello, en nuestra escena mítica, fijado a partir del rapto de Perséfone.

La vinculación con la fertilidad no solo le llega a Baubo en relación con la rana, sino también con el cerdo. De la relación entre Baubo y este animal se hacen ecos algunos elementos culturales como el que encontramos, por ejemplo, en la escena del Fausto de Goethe, en la Walpurgisnacht, donde la vieja bruja Baubo aparece sobre una cerda, recuerdo de terracotas de tipo Baubo donde las figuraciones muestran su vulva encima de cerdos, antiguo símbolo de renacimiento y parto, de fecundidad, de nutrición o de alimento, por lo que puede encarnar los aspectos tanto de fertilidad, como de recurso nutricio. No olvidemos la caracterización de Baubo como la comadrona, niñera o nutricia de Deméter, aquella que cuida, que alimenta el ánimo y el cuerpo de Deméter, con risa y con bebida o como la que pare simbólicamente al hijo de Deméter, para devolverla a la vida. Por otro lado, en un plano menos espiritual o místico, desde la pura cotidianidad, el cerdo implica bonanza entendida como garantía de supervivencia, como afirmación de una fuerza vital. 
Por tanto, animal símbolo de la fertilidad, de la bonanza, del alimento que, que como indica Georges Devereux, entraba en juego en las festividades dedicadas a Démeter, Perséfone y Baubo a través del ofrecimiento como sacrificio sagrado a las diosas eleusinas. Por último, no hemos de pasar por alto el apunte que nos hace el autor: Dionisos Choiropsalas, deidad de la fertilidad, significa Dionisos 'el que acaricia un cerdo' o el que 'acaricia una vulva', puesto que choiro designa 'cerdo' y 'vulva' (Devereux, 1984: 45-46).

Encontramos, en una de las versiones que recopilamos, en concreto la que hemos presentado de la mano de Karl Kerényi, otra base para la relación con este animal: Baubo, campesina, tiene una piara que cuida su hijo, que es quien puede indicar a Deméter dónde se encuentra Perséfone, dado que cuando cuidaba de sus cerdos vio como eran engullidos por la tierra cuando esta se abrió para dar paso al carro de Hades, quien perpetraba el secuestro de Perséfone.

En cualquier caso, tanto con la «Baubo-rana» como con la «Baubo-cerda» o la «Baubo-vulva» es clara la referencia a algo fundamental para la sociedad, a saber: la fertilidad de la tierra y de las mujeres, garantes de futuro, dado que si se puede asegurar una legítima descendencia y una cosecha cuanto menos suficiente, el porvenir de la comunidad estará asegurado.

\section{Yambe}

Según Laurie O’Higgins en «Baubo and the Cult of Demeter» la aparición de la joven Yambe responde a una estrategia para disimular lo obsceno de la escena entre Baubo y Deméter, a fin de volverla más decorosa. A diferencia de Baubo y a pesar de que Yambe haga burlas y haga referencia a aspectos sexuales, esta goza de cierta respetabilidad frente a una mujer que decide mostrar su sexo. O'Higgins escribe:

Este testimonio de carácter formulista y el silencio del Himno con respecto al tema (sexual) de sus bromas, la distancian de su contraparte de mala reputación, Baubo, una mujer asociada con los cultos de Deméter. Sugiero que esta cuidadosa distinción fue parte de la estrategia general del Himno: apropiarse del material de culto de las mujeres en un orden social dirigido por hombres. La inaceptable vulgaridad de Baubo estaba vinculada a un poder y una autoridad que los poetas del Himno deseaban conservar, pero en una versión alternativa saneada. (2003: 51. Nuestra traducción)

Por otro lado, en la versión referida de Robert Graves se aúna en la escena mítica tanto Baubo como Yambe y sostiene que «Yambe, Deméter y Baubo forman la tríada de doncella, ninfa y vieja. Las viejas niñeras de los mitos griegos casi siempre representan a la diosa como anciana» (1996: 92).

\section{Deméter}

Deméter es una de las figuraciones griegas de la madre tierra, también conocida como madre de los cereales, de las semillas, de la agricultura y del ciclo de las 
estaciones. Representa la potencia o la fuerza que hace que el grano crezca, se desarrolle y se reproduzca hasta desaparecer. Es señalable, que el mito del rapto de Perséfone, daría cuenta del ciclo de la estaciones, entre otras cosas. Autoras como Catherine Blackledge relacionan a Deméter, a Perséfone y a Hécate con las diosas egipcias Hathor e Isis, también figuraciones de la fertilidad, de la fecundidad, no solo referidas a las intrínsecas capacidades reproductivas, sino también vinculadas con el brotar de la naturaleza y de la vida en general - Isis como resucitadora y madre de Horus y Hathor como madre de los faraones representaban el seno nutricio de todo su pueblo, de toda su descendencia- (2004: 20-28). Figuran la vida como ciclo de las estaciones y/o como ciclo vida-muerte. A lo que apuntamos con nuestra interpretación es que el gesto de Baubo, el que reanima a Deméter y con ella, vuelve fértil la tierra, se enmarca en este poder al que apuntan las figuras mencionadas. Estas diosas presentan una potencia, una fuerza específicamente ligadas a ellas: la regeneración, la resurrección, el renacimiento, en definitiva, el devenir del mundo.

Sarah Kofman, así como Mithu M. Sanyal en Vulva. La revelación del sexo invisible (2012: 39-42) o Catherine Blackledge en The Story of V. (2004: 19-21) rescatan la referencia a una leyenda japonesa sobre la diosa sintoísta Amaterasu, quien profundamente herida por su hermano, se refugia en una cueva. La consecuencia es que la vegetación y la tierra comienzan a morir, puesto que esta deidad es la diosa del sol. Los dioses no saben qué hacer (como los dioses griegos durante la melancolía de Deméter). Nuestra Baubo sintoísta será Ame-no-Uzume: ella logra revitalizar a la diosa escondida a través de una danza —el gesto de Baubo será interpretado por Kerényi como una «danza obscena» (2004: 64). En el momento álgido del baile, se arranca la vestimenta y queda desnuda, o según otras fuentes, se levanta la falda y deja al aire sus senos. Al ver la vulva de la danzante, Amaterasu se ríe y, con ella, el resto de dioses. Amaterasu sale de la cueva y devuelve la fertilidad a la tierra.

Es destacable que el dolor de las diosas hunde su raíz en un acto derivado de una impetuosa violencia de una figura masculina, bien sea Hades con el rapto de Perséfone, bien sea Susanoo, dios de la tormenta sintoísta, hermano de Amaterasu. Ante tales actos crueles, ninguno de los dos panteones sabe qué hacer para remediar el exacerbado dolor de las diosas. Salvo dos mujeres que con la danza, la broma, el gesto, traen a estas figuras la fertilidad de nuevo, en un espacio de amabilidad, risa: de invitación al retorno a la vida.

\section{El gesto de Baubo}

El acto de Baubo ha sido interpretado como un gesto mágico cuyo fin es devolver la fertilidad, la vida a la tierra como extensión de Deméter, ya que pone término a la errancia melancólica de Deméter. No obstante, siguiendo las pistas que nos da Kofman, podemos sospechar que no solo es una escena mágica para devolver la fertilidad, sino también para dar lugar a un espacio al margen de lo masculino. A propósito de esta cuestión, destacamos algunas referencias de leyendas que nos traen varias autoras, en las que aparece este gesto, que hace referencia tanto a una 
broma lasciva u obscena, como a un gesto erótico, invocación de la fertilidad y que, al mismo tiempo, ha cumplido en la cultura un papel apotropaico como mecanismo de defensa ritual ${ }^{5}$ :

En Japón existe una leyenda que narra como dos mujeres perseguidas por demonios intentan escapar en una barca de remos pese a que los demonios son más rápidos; en el último instante se les aparece una diosa y les aconseja descubrir sus órganos genitales. Al ver que ambas dudan, la diosa les muestra el suyo y estas la imitan, de forma que los demonios, aullando de risa, renuncian a la cacería. Además de la correspondencia con Baubo, la mitología egipcia tiene también un equivalente [...] a la diosa ayudante de la leyenda; se trata de Hathor, quien calma al dios solar Ra desnudando su genital. En la mitología griega, las mujeres de la ciudad de Xantos obligan al invencible héroe Belerofonte - conocido por haber domesticado al caballo volador Pegaso- a emprender la huida mostrándole de forma colectiva su sexo. Y los autores antiguos Plinio y Plutarco informan incluso de dioses que se dan a la fuga ante la visión de la vulva descubierta. El mítico o héroe irlandés Cuchulain es disuadido de luchar contra su propio pueblo por ciento cincuenta mujeres que alzan sus faldas al mismo tiempo. (Sanyal, 2012: 41-42)

\section{Ahora detengámonos en el siguiente fragmento de Kofman:}

[Estas leyendas] permiten afirmar que por todas partes, cuando una mujer se levanta las faldas provoca la risa o la huida, de tal manera que este gesto puede ser utilizado como medida apotropaica: el vientre de la mujer juega el papel de la cabeza de Medusa. ¿Levantando sus faldas, Baubo no invitaría a ir a asustar a Hades, o lo que es lo mismo, no recuerda su fecundidad a Deméter? Mostrando sobre su vientre el rostro de Dionisos, ella recuerda el eterno retorno de la vida. (1979: 294-295. Nuestra traducción.)

Espantar a los demonios, mantener lejos las fuerzas hostiles que raptan a las hijas, que humillan y destrozan la casa propia, como en el caso de la diosa sintoísta Amaterasu, implica, precisamente, lograr un espacio sororo entre mujeres que, por otro lado, espantaría, como la cabeza de Medusa: una alianza entre mujeres parece que es el verdadero peligro contra el que lucha el patriarcado.

Como vemos, este extraño gesto de Baubo (sustituido en algunas fuentes por las chanzas y burlas de Yambe) ha hecho reflexionar a más de una persona. El gesto de Baubo, en el que se levanta su peplo, túnica que vestían las mujeres en la antigua Grecia, y con el que exhibe su genital ante la diosa de la fertilidad y representante del ciclo vida y muerte (unida a su hija, Perséfone), se repite a lo largo de distintas tradiciones. Así, encontramos toda una constelación de gestos que reciben el nombre de anasyrma (también ana-suromai). El termino se extiende hasta el punto de designar a las obras de arte en las que aparezca este gesto, como ejemplo en la ilustración Le diable Papefiguiere de Charles Eisen para los cuentos de La Fontaine. Por otro lado, encontramos la aischrologia, la licencia verbal que se toma Yambe en

5 Para encontrar un recopilatorio sobre el carácter apotropaico de la vulva recomendamos acudir a Mithu M. Sanyal. Vulva, La revelación del sexo invisible (2012: 41-44). 
sus chanzas (cf. Castro Jiménez, 1991: 136 y Vernant, 2001: 46), que proviene de aischrologéin y podemos entender como 'lenguaje vulgar' (Devereux, 1984: 30).

El marco donde adquieren verdadera relevancia estos gestos rituales o mágicos aparece en las Tesmoforias y en los ritos eleusinos. Catherine Blackledge explica que el ritual del ana-suromai está íntimamente ligado a las figuras de Deméter, Perséfone y Baubo y a sus misterios. Según Blackledge, suponían la celebración de la potencia del «sexo femenino, reflejada en la escena de Baubo-Deméter, representada en los misterios, ritos y festivales» (2004: 22). No obstante, lo llamativo aquí es que este gesto ana-suromai se encuentra en otras culturas, no solo en la griega, de ello dan cuenta innumerables figurillas de «tipo Baubo»: antiquísimas imágenes de orgullo y disfrute de unos genitales. Un disfrute y una exhibición sin obscenidad, sin vergüenza, más bien, tal y como apunta Blackledge, con dignidad.

Retomando la cuestión desde el ámbito enmarcado en la antigua Grecia encontramos que se trata de un gesto que hace su aparición entre otras bromas explícitamente sexuales en los cultos a Deméter-Perséfone y Dionisos. De los primeros, que son los que aquí consideraremos, tomamos los gestos, bromas y risas que las mujeres pondrían en juego durante las Tesmoforias, fiestas a las que acudían mujeres casadas en un espacio al margen de los hombres y al margen del hogar: «La ocasión se presenta, entonces, también, como un tiempo para la reunión en un espacio propio, común al genos gunaikon, de encuentro y de afirmación femeninos» (Valdés Guía, 2015: 13).

Fiestas consagradas a las diosas Deméter y Perséfone, en rituales cargados de alusiones eróticas; de semillas y flores, representantes de las fuerzas vitales que implican, en su ciclo, necesariamente pasar por la muerte para que haya un resurgir, un brotar de nuevo. En ese sentido podemos hablar de estas deidades como deidades de la vida y de la muerte, diosas del devenir (cf. García Gual, 2003: 21). En las Tesmoforias se representa simbólicamente el ciclo durante tres días. El primer día, Anodos, en el que se accedía y se conformaba el espacio sagrado y festivo.

El segundo día, Nesteia, era día de ayuno, se comían semillas de granada, se tumbaban sobre plantas anafrodisiacas — sofocaban su libido-, unidas en el luto a Deméter (cf. Valdés Guía, 2015: 20-21) y, al mismo tiempo, a Perséfone probando la comida del Hades, que en el mito, la atará ineludiblemente a él. Encontramos, por tanto, la «imagen de la «muerte ritual» de la joven» (Valdés Guía, 2015: 17) y la puesta en suspenso del sexo, lo que implica infertilidad.

El día siguiente, será el del renacimiento, denominado Kalligeneia, de Caligenia, nodriza de Deméter (como es Baubo en algunas versiones), etimológicamente, la del bello origen. En este tercer día se invocan a las diosas del nacimiento (Ilitia) y a las comadronas (nuevo vínculo con Baubo). El renacimiento revive a la tierra, a Deméter y a Perséfone, dado que es un recordatorio del encuentro entre las diosas. Este es el día en el que se ponen en juego la anasyrma, la aischrología, la obscenidad $y$, con ello, se pone fin al ayuno. Reflejo de lo que ocurre en la escena mítica: en un primer tiempo Deméter vaga por la tierra desolada; en un segundo momento, se le ofrecerá bebida que rechazará. Solo la beberá en un tercer momento en el que, tras reír a causa de Baubo-Yambe, accede a la invitación de su compañera. 
El último día, al mismo tiempo que una liberación de lo que ha estado reprimido en el espacio de la polis y del hogar, supone una preparación para (y una reparación de) lo cívico, para asumir de nuevo la imposición de silencio, de represión y de pudor, pues tras la aischrología ritual, vuelven a un espacio que parece que juega en favor de una determinada economía sexual que no es la de las mujeres (cf. Maseda, 2020: 451-456). En estos espacios no hostiles entre mujeres, en el que no entran en rivalidad ni competencia, en los que no reprimen todo aquello que sí han de reprimir en el espacio público dominado por los hombres, puede darse la posibilidad de un discurso distinto para ellas, de una experiencia discursiva no dominada por el respeto que han de tener y tenerse para ser mujeres dignas. A propósito de esta cuestión, Miriam Valdés escribe:

[...] en la fiesta se encuentran signos, ritos e indicios de animadversión y de reversión femenina frente a la civilización y el mundo ordenado por el varón, lo que podría indicar la existencia de un contradiscurso o al menos, la posibilidad de discursos paralelos y en ocasiones divergentes al de los varones. (2015: 22)

Después de estos días festivos volverán a ser mujeres decentes y cívicas, privadas del derecho a la palabra (sea obscena o no). Miriam Valdés Guía busca, precisamente, un discurso alternativo al de los varones en este contexto permisivo a la vez que regulador de las fiestas tesmofóricas.

De este modo la licencia verbal vinculada, en la aischrologia, a la sexualidad (con la ironía y sentido del humor propios que se puede intuir), y, en general, en la fiesta, y de modo específico en Kalligeneia, el conocimiento, transmitido de madres a hijas, asociado a la concepción (posiblemente contrapuesto a la idea de la generación originada únicamente por el varón), entre otros aspectos (visiones o espacios diferentes, por ejemplo, de la justicia), formarían parte de un discurso (o discursos) compartidos del genos gynaikon, percibidos no sólo con desconfianza por los hombres, sino como peligrosos para ellos, pero permitidos, de forma acotada en el ritual, por el poder inherente y necesario de la mujer en el ámbito de la fecundidad y, consecuentemente, de la perpetuación de la polis. (Valdés Guía, 2015: 24)

Espacio de libertad para algunas mujeres, las consideradas decentes: de buena familia y casadas (cf. García Gual, 2003: 21), que muestran capacidad de alianza y discurso, partiendo de su propia inmanencia elevándose en la complicidad y en la puesta en común de la experiencia, para elaborar el ciclo vida-muerte más allá de los valores de los varones que los instauran y, en ello, ostentan un saber secreto y oculto a sus ojos: saber sobre la menstruación, sobre los ciclos, sobre la fertilidad, sobre la concepción, sobre su placer, sobre su cuerpo, sobre el dolor de la imposición, del rapto, de la violencia. Todo ello, unido en la figura de Deméter. Oculto y restringido a la fiesta (espacio ritualizado en el que puede asomar lo amenazador, regulado por las normas sagradas), un espacio donde aparece o bien algo espantoso que hace huir o algo ridículo que hace reír. Al margen del varón, pero, como apunta Valdés, inmerso en su dinámica: el espacio está cedido por la lógica regida por el varón, la de la polis. 
Por esto mismo, tampoco habríamos de dejarnos llevar por una ilusión romántica sobre la alianza femenina y mitificarla. Su origen era la opresión y represión, además de la regularización, purificación y estimulación de sus cuerpos, con miras a sus funciones reproductivas. Por otro lado, podemos interpretar la vulgaridad, las bromas lascivas como un punto de fuga dentro del silencio-pudor que era ley.

\section{El ciceón y la risa}

El kykeon o ciceón es una bebida sagrada que en los misterios de Eleusis simboliza el fin del ayuno sagrado. Remite al momento mítico en el que Deméter logra romper su ayuno aceptando la bebida, aceptando la vida. El ciceón era una mezcla de agua, cebada y hierbas, según los relatos tenía propiedades digestivas. En relación con nuestra escena, simboliza la digestión de la pérdida de Perséfone, dado que la diosa logra sobreponerse a la melancolía. En una de las escenas que leímos en el segundo punto de nuestro desarrollo, vemos que Deméter rechaza la copa de vino que Yambe le ofrece, el vino no será su bebida. No obstante, ella pide su bebida, la que le es propia, no la de la uva, sino la de la cebada y la menta, hierba que, como Miriam Valdés señala, es emenagoga, es decir, que estimula flujo sanguíneo del área de la pelvis y el útero, estimula la menstruación. Así, al calor sexual, dionisiaco, que pudiera causar el vino (podemos pensarlo como una bebida que favorece la concepción), se contrapone el ciceón que fomenta la digestión y la anticoncepción y que, sin embargo, recupera otra fertilidad de la diosa: favorece el retornar, el salir de la melancolía y, por extensión en el relato, la propia fertilidad de la tierra, entendida como recuperación del ciclo vida-muerte. Por otra parte, en la línea de lo que comentábamos sobre el saber oculto, podríamos ligarlo aquí con el saber sobre las propiedades de las plantas y alimentos en relación con las capacidades reproductivas, ya sea para la regulación de la menstruación, para adelantarla o atrasarla, para provocar un aborto o para aumentar la fertilidad; citando de nuevo a Miriam Valdés Guía: «Esto lleva a pensar en un conocimiento ginecológico tradicional de las mujeres que podría transmitirse internamente, en contextos como el tesmofórico - entre otros-》 (2015: 24).

Lo llamativo de lo dicho hasta ahora es que en esta alianza y comunidad de mujeres, ninguna, siguiendo el ejemplo de Baubo, se avergüenza de su sexo, de su potencialidad, pero tampoco se vergüenza de su saber, ni de su discurso. La risa parece aquí la válvula de lo reprimido. Freud, en El chiste y su relación con lo inconsciente, dirá que es un mecanismo de defensa del yo, para protegerse, para sobrevivir ante lo intolerable. El gesto de Baubo, como hemos visto, es la contrapartida, la otra cara de la risa de Deméter, un binomio inseparable, mecanismo de defensa para ahuyentar el mal, a saber, el dolor y la violencia causada sobre Deméter (por la violencia ejercida sobre Perséfone, no queremos perder del horizonte esto).

En conjunto, podríamos proponer una interpretación general de la escena en la que en este deambular de Deméter, la tierra se ha vuelto estéril, como la propia diosa, impotente, al haber perdido a su hija, o mejor dicho, al haberle arrebatado a Perséfone. En este tránsito melancólico hacia ninguna parte, encuentra a Baubo, 
la cual se levanta las faldas, mostrando su vientre sobre el cual se encuentra dibujada la figura de Yaco, hijo de Deméter, a veces identificado con Dionisos (Kofman, 1973: 64 y 1979: 295); en otra versión Baubo se levanta las faldas y no solo muestra su sexo, sino que además pare, da a luz, a Yaco, reminiscencia de la fecundidad de la diosa, de la creación y de la afirmación, enmarcada en lo que Kofman llamará una historia de mujeres (Deméter, Baubo, Perséfone) que aleja el mal augurio, la muerte, la esterilidad. En efecto: asistimos a una escena en la que no se logra aliviar el dolor por arte de magia, sino que lo que acontece es una afirmación de la vida, en su radicalidad, en la invitación entre mujeres, pues la mezcla de cebada, agua y hierbas solo es aceptada -es decir, solo se da la posibilidad de digestión- cuando Baubo se convierte en el sexo femenino, en la potencia, en el aumento. Una vulva mítica, que es al mismo tiempo la de Deméter, como si se tratase de un gesto simbólicamente especular. Así, la vulva de Baubo y la risa de Deméter recuerdan el eterno retorno de la vida, en una complicidad que queda por fuera de la polis, de los dioses y sus artimañas, en una afirmación risueña, ligera, jovial.

\section{4.- Conclusiones o derivas de nuestro planteamiento}

El lugar de las mujeres o de las figuraciones y arquetipos femeninos han venido trazados por los hombres y, como sostendrá Kofman, en defensa de su economía sexual, que en última instancia responde a lo que Freud llamará «angustia de castración». Una angustia, que si no nos limitamos a leer el relato edípico freudiano como: «matar al padre, acostarse con la madre», podemos interpretar que va más allá y que está en relación con el límite, con la negación de algo, con la imposibilidad del control total y con los delirios de omnipotencia. Los actos «matar al padre, acostarse con la madre» aparecen como límite absoluto de la condición humana para Freud. Edipo sobrepasa todo límite humano. De hecho, la cultura o el proceso de civilización para el vienés reposa en la interiorización de la negación, en la imposición de límites: esto no se puede y aquello tampoco. En cualquier caso, para Kofman, la economía sexual masculina está regida por esta angustia de castración: angustia ante el límite representado por la diferencia que, tradicionalmente, para los hombres, ha encarnado siempre el extranjero, pero más angustiosa y exactamente las mujeres, la otredad por antonomasia (cf. Maseda, 2020: 504). En todo este enredo cultural, nos parece un buen intento el sacar a la luz relatos que no expongan esta lógica económica y nos permitan construir otra: la de la alianza de las mujeres, más allá de elaboraciones fetichistas.

La amenaza de castración pende sobre aquellos que temen ser castrados. El mecanismo fetichista actuará como mecanismo de defensa a fin de neutralizar y evitar la parálisis que conlleva tal angustia (cf. Maseda, 2020: 253, 343 y ss.). Una parálisis que Sarah Kofman no duda en vincular a la causada por Medusa: su monstruosidad se representa con una cabellera de serpientes y una mirada petrificante. Figura mitológica bastamente tratada en el ámbito inaugurado por Freud, puesto que su cabellera de serpientes es un desplazamiento de una melena llena de falos, donde la abundancia de los mismos apunta a la misma ausencia de él, es decir, al sexo 
femenino (Ferenczi, 1967: 296, Freud, 1940 [1922], Kofman, 1997: 101 y Maseda, 2020: 400).

Una de las caras de esta defensa supondría proyectar la causa de esta amenaza sobre las mujeres. Una defensa, de nuevo, fetichista - de ver y no querer ver al mismo tiempo, contar con algo pero negarlo a la vez-construida sobre estrategias que merman su libertad de movimiento y sexual, enclaustradas en la casa y en la maternidad; o bien que las convierten en seres despreciables (monstruosos) que apenas rozan lo humano o en diosas intocables por inalcanzables (cf. Maseda, 2020: $450,483,521)$ y siempre, separadas unas de las otras. Divide et impera. En Le respect des femmes, Kofman afronta esta estrategia camuflada a lo largo de la historia bajo el sentimiento de respeto hacia las mujeres, hacia esos seres que son seres humanos, pero que además conforman un conjunto especial de seres con los que habremos de emplear un tipo especial de respeto, no en tanto que personas, sino por su sexo (cf. Maseda, 2020: 450-453). Un respeto que las mujeres han de ganarse en disputa con otras mujeres: ser la más pudorosa, la más bella, la más casta, y otras lindezas que ya conocemos gracias al desmantelamiento de los estereotipos que ha llevado a cabo el movimiento feminista.

De nuevo, divide y reinarás, en este caso, con un mecanismo de control llamado pudor, aquello que la naturaleza, dios o la entidad fundante de un determinado sistema de creencias ha dotado a las mujeres para desactivar ese poder que conlleva la amenaza que suponen (la diferencia y el límite en sí mismo). Así, «una mujer sin pudor es una criminal; una vez que se quita ese freno, no hay sujeción, retención, alguna» (Kofman, 1982: 86. Nuestra traducción). Baubo, en este sentido, será una mujer criminal, precisamente, por poner en cuestión la alianza entre lo civil y lo natural: que se funda en el recato de este otro sexo que no es el hegemónico, el que construye la realidad y la ley, los usos y las costumbres. El que tiene la vara de medir, es decir, el que emite valores, valoraciones, normas y preceptos. Una economía sexual que condena a Circe, pero adora a Atenea. De lo que se trata es de romper esa valoración: ni condenar a Circe, ni adorar a Atenea, sino con ellas. Ello implica, necesariamente, un espacio sin rivalidades, sin competición por ostentar algo que no es nuestro, efectivamente, el falo en disputa. Baubo y Deméter no están solas, logran acompañarse, hermanarse, reírse y afirmar la vida, en un espacio ajeno a cualquier tipo de lógica fálica. Podría argumentarse que en el caso de la versión del mito en la que Yaco está dibujado en el vientre de Baubo o, mejor aún, que en el relato en el que Baubo pare a Yaco, aparece este como el sustituto del falo, es decir, que está inmerso en una lógica, de nuevo, fálica. Sin embargo, para que esto se dé hay que pasar, como ilustra el mito mediante el vagar penoso de Deméter, por un momento de ausencia, de pérdida, de separación (desde una vertiente psicoanalítica, de castración) que solo en el momento de la interacción con Baubo logra afrontar y asumir.

Solo es posible el cambio, el movimiento, si hay una privación, digamos, un lugar vacío al que algo pueda venir. Solo si se reconoce ese lugar vacío, esa falta, podrá haber lugar para lo que esté por venir. Sea una criatura, sea una alianza, sea una carcajada: en cualquier caso, se pasa por la asunción de algo que la lógica fálica 
trata de ocultar a todo coste, a saber, la diferencia, la pérdida, la muerte, el límite, el vacío. Lo que rompe y quiebra la cotidianidad. ¿Para qué otra cosa estarían entonces los usos y las costumbres, la ley, lo cívico? Para acabar con la obscenidad de la sangre, del sudor, de las lágrimas. Para acabar con aquello que ni es agradable ni reconfortante. En el pensamiento de Sarah Kofman, heredera de las metodologías planteadas por Freud y Nietzsche, la raíz de este mecanismo está en desconocer la diferencia sexual o en el fetichismo.

La escena propuesta por nuestra filósofa nos parece que constituye una bella figuración de la posibilidad de una salida del reino del sexo fálico, en la que Baubo resiste al pudor impuesto y se vuelve una mujer obscena: se levanta su peplo y muestra su renuncia a quedar confinada en una lógica mortificadora que impide la alianza entre mujeres. Deméter y Baubo, ambas obscenas, una exhibiendo y la otra mirando, ríen conscientes de aquello que el mecanismo fetichista les impone: la separación, la silenciosa mortificación, la soledad, el sufrir las penas al margen de la cotidianidad. En una escena, además, que no puede estar más rodeada de lo cotidiano: una bebida, una comida; la hospitalidad; la invitación y la risa, entre figuraciones femeninas que no se representan omnipotentes, ni puras; que nos revelan un reino que no es ni de monstruosas Medusas, ni seductoras Circes, ni vírgenes Ateneas, ni salvajes Artemisas. Lo que se perfila es un espacio donde no hay un poder jerárquico, ni una valoración, sino un gesto que no responde a la lógica de lo medible, cuantificable, formulable, etc., en el que las mujeres son humanas, sencillamente humanas: «La figura de Baubo implica una lógica simple: [...] la risa afirmativa de un viviente que dice que, a pesar de la muerte, la vida puede retornar indefinidamente» (Kofman, 1979: 295. Nuestra traducción).

\section{Bibliografía}

(1978). «Deméter» en Himnos Homéricos. «La Batracomiomaquia», Madrid: Gredos.

Agamben, Giorgio y Monica Ferrando (2010). La ragazza indicibile: Mito e mistero di Kore, Milán: Electa.

BLACKLEDGE, Catherine (2004). The Story of $V$ : a natural history of female sexuality, New Brunswick, New Jersey: Rutgers University Press.

Castro Jiménez, Ma Dolores (1991). El mito de Proserpina: Fuentes grecolatinas y pervivencia en la literatura española. Tesis Doctoral. Universidad Complutense de Madrid. Disponible en: https://eprints.ucm.es/3247/1/T16823.pdf (Fecha de consulta: 08/01/2021).

Chantraine, Pierre (1968). Dictionnaire étymologique de la langue grecque, París: Klincksieck. Disponible en: https://archive.org/stream/Dictionnaire-Etymologique-Grec/Chantraiine-DictionnaireEtymologiqueGrec\#page/n183/ mode/2up (Fecha de consulta: 23/12/2020).

Clemente de Alejandría (2008). Protréptico, Madrid: Gredos.

Devereux, Georges (1984). Baubo. La vulva mítica, Barcelona: Icaria.

FERENCZI, Sándor (1967). «Sobre el simbolismo de la cabeza de medusa» en Teoría y técnica del psicoanálisis, Buenos Aires: Paidós. 
Forlong, John G. R. (2008). «Baubo» en Encyclopedia of Religions, vol. I: A-D, New York: Cosimo classics. Disponible en: https:/ / books.google.es/books?id=LDoE SIYRyMEC\&printsec $=$ frontcover\&hl=es\#v=onepage \&q\&f=false $($ Fecha de consulta: 05/01/2021).

Freud, Sigmund (1916). «Paralelo mitológico de una representación obsesiva plástica» en Obras completas, vol. XIV, Buenos Aires: Amorrortu, 1979.

Freud, Sigmund (1923). «La organización genital infantil», en Obras completas, vol. XIX, Buenos Aires: Amorrortu, 1979.

Freud, Sigmund (1940 [1922]). «La cabeza de Medusa» en Obras completas, vol. XVIII, Buenos Aires: Amorrortu, 1979.

García Gual, Carlos (2003). Diccionario de mitos, Madrid: Siglo XXI.

Gimbutas, Marija (1999). The Living Goddesses, California: University of California.

GoETHE, Johann W. (2006). «Noche de Walpurgis» y «El carnaval romano» en Fausto I, Madrid: Alianza.

Graves, Robert (1996). The Greek myths, vol. I, Londres: The Folio Society.

Guthrie Chambers, William K. (1970). Orfeo y la religión griega. Estudio sobre el «movimiento órfico», Buenos Aires: EUDEBA.

Harrison, Jane H. (1908). Prolegomena to the Study of Greek Religion, Cambridge: University Press.

KeRÉNYI, Karl (1994). «Hombre primitivo y misterio» en Círculo Eranos I: Arquetipos y símbolos colectivos, Barcelona: Anthropos.

KERÉNYI, Karl (2004). Eleusis. Imagen arquetíicica de la madre y de la hija, Madrid: Siruela.

Kofman, Sarah (1973). Camera obscura de l'idéologie, París: Galilée.

Kofman, Sarah (1979). «Baubô, perversion théologique et fétichisme» en Nietzsche et la scène philosophique, París: Galilée, pp. 263-304.

Kofman, Sarah (1982). Le respect des femmes, París: Galilée.

Kofman, Sarah (1997). El enigma de la mujer, Barcelona: Gedisa.

Lenormant, François. (1877). «Baubo» en Dictionnaire des antiquités grecques et romaines, Tomo I, primera parte (A-B), París: Hachette. Disponible en: https:// books.google.es/books?id=Jg4HbrxWb5AC\&pg=PA1\&dq=Dictionnaire+des + antiquit $\%$ C3\%A9s+grecques+et+romaines\&hl=es\&sa=X\&ved=2ahUKEwiF 6dCKioLuAhVIz4UKHai4D44Q6AEwAXoECAYQAg\#v=onepage\&q\&f=false (Fecha de consulta: 20/12/2020).

Lubell, Winifred M. (1994). The Metamorphosis of Baubo: Myths of Woman's Sexual Energy, Nashville: Vanderbilt University Press.

Marcovich, M. (1986). Demeter, Baubo, Iacchus, and a Redactor. Vigiliae Christianae, Septiembre, vol. 40, n⿳3 3, pp. 294-301. Disponible en: https://www.jstor.org/ stable/1583904?seq=1 (Fecha de consulta: 22/12/2020).

MASEDA DE LA TORRE, Susana (2020). Habitando el entre: estética, literatura y psicoanálisis en Sarah Kofman. Tesis doctoral inédita. Universidad Complutense de Madrid.

MurraY, Margaret (1934). «Female Fertility Figures» en The Journal of the Royal Anthropological Institute of Great Britain and Ireland, Enero-Junio, vol. 64, pp. 93100. Disponible en: https://www.jstor.org/stable/2843950 (Fecha de consulta: $27 / 12 / 2020)$. 
NiEtzsche, Friedrich (2014). «La gaya ciencia» en Obras completas, vol. III, Madrid: Tecnos.

O'Higgins, Laurie (2003). «Baubo and the Cult of Demeter» en Women and Humor in Classical Greece, Cambridge: Cambridge University Press.

Olender, Maurice (1985). «Aspects du Baubo, texte et contextes antiques» en Revue de Histoire des religions, 202-1, pp. 3-55. Disponible en : https: / /www.persee.fr/ doc/rhr_0035-1423_1985_num_202_1_2785 (Fecha de consulta: 27/12/2020).

PicARD, Charles (1927). «L'épisode de Baubo dans les Mystères d'Eleusis» en Revue de l'histoire des Religions, pp. 220-250. Disponible en : https://www.jstor.org/ stable/23664588 (Fecha de consulta: 01/01/2021).

SAnYal, Mithu M. (2012). Vulva. La revelación del sexo invisible, Barcelona: Anagrama.

Smith, William, ed. (1876). Dictionary of Greek and Roman Biography and Mythology, vol. II, Londres: John Murray. Disponible en: https: / archive.org/details/adictionarygree00smitgoog/page/n7/mode/2up (Fecha de consulta: 20/12/2020).

VAldés Guía, Miriam (2015). «La risa de Deméter» en Arys, 13, pp. 9-25. Disponible en: https:/ / e-revistas.uc3m.es/index.php/ARYS/article/view/2748 (Fecha de consulta: 03/01/2020).

VERnANt, Jean-Pierre (2001). La muerte en los ojos: Figuras del Otro en la antigua Grecia, Barcelona: Gedisa.

Recibido el 13 de enero de 2021 Aceptado el 23 de marzo de 2021 BIBLID [1132-8231 (2021): 65-81] 